2. To: (Receiving Organization)

Distribution

5. Proj./Prog./Dept./Div.:

8. Originator Remarks:

For Approval

11. Receiver Remarks:

11A. Design Baseline Document? [x]-Yes No MaB

SGN Eurisys Services Corp.

GA Barnes. 08E00

Engr.:

GP Janicek
Characterization

4. Related EDT No.:

NA

6. Design Authority/ Design Agent/Cog.

9. Equip./Component No.:

NA

10. System/Bldg./Facility:

200Gen

12. Major Assm. Dwg. No.:

NA

13. Permit/Permit Application No.:

NA

14. Required Response Date: $2 / 24 / 98$

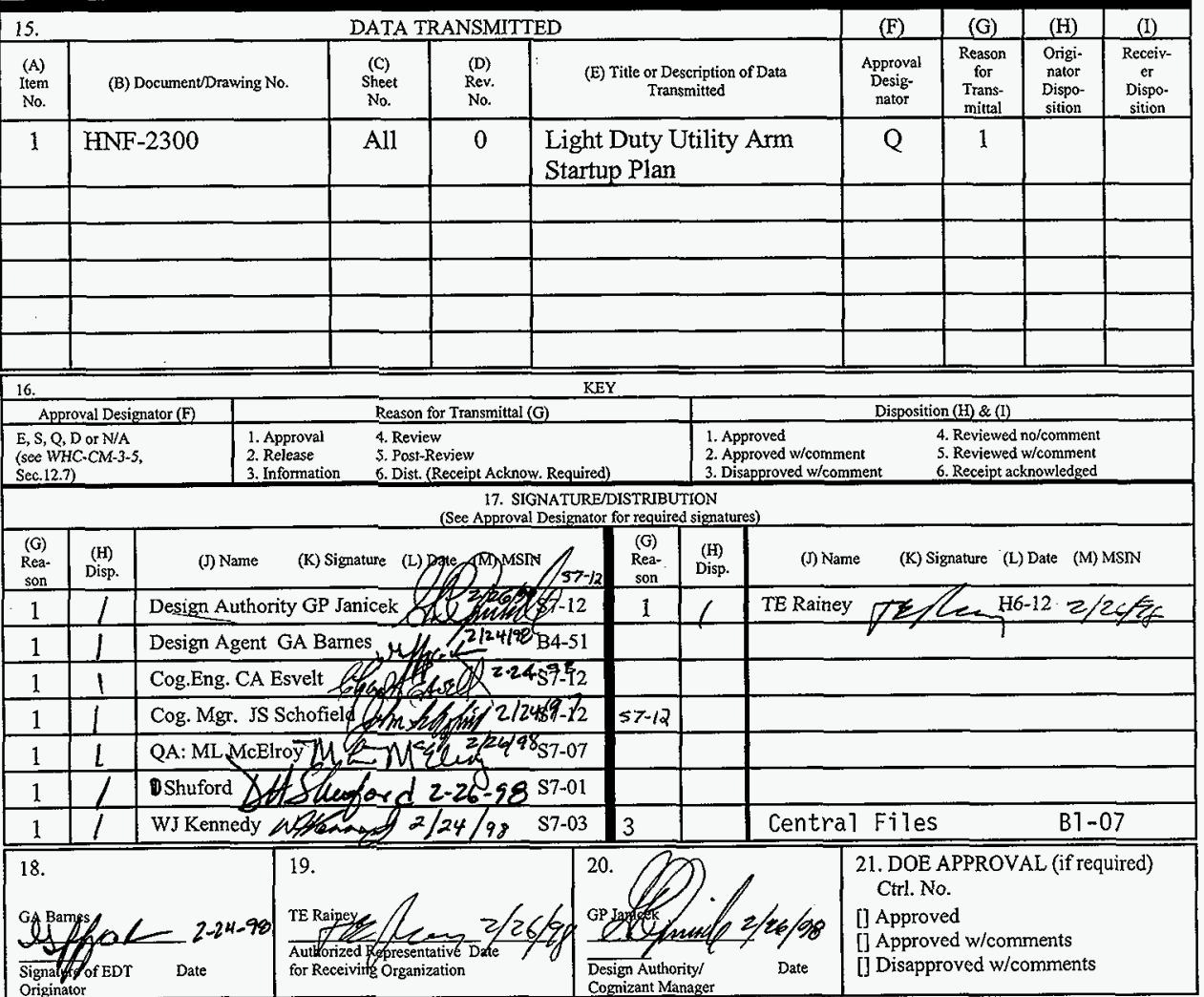


HNF-2300, Rev. 0

\section{LIGHT DUTY UTILITY ARM STARTUP PLAN}

6. A. Barnes, SEN Eurisys Services Corp. for Lockheed Martin Hanford Corporation, Richland, WA 99352

U.S. Department of Energy Contract DE-AC06-96RL13200

$\begin{array}{lll}\text { EDT/ECN: } & 623833 & \text { UC: } 2070 \\ \text { Org Code: } & 08 E 00 & \text { Charge Code: LME020 } \\ \text { B\&R Code: } & \text { EW3120074 } & \text { Total Pages: } 21\end{array}$

Key Words: Light Duty Utility Arm (LDUA), startup plan, Facility Group 3 tanks, end effectors

Abstract: This Startup Plan encompasses activities necessary to perform startup and operation of the LDUA in Facility Group 3 tanks and complete turnover to CPO. The activities discussed in this plan will occur prior to, and following the U.S. Department Energy, Richland Operations Office Operational Readiness Review. This startup plan does not authorize or direct any specific field activities or authorize a change of configuration. As such, this startup plan need not be Unresolved Safety Question (USQ) screened.

TRADEMARK DISCLAIMER. Reference herein to any specific compercial product, process, or service by trade name, trademark, manufacturer, or otherwise, does not necessarily constitute or imply its endorsement, reconmendation, or favoring by the United States Government or any agency thereof or its contractors or subcontractors.

Printed in the United states of America. To obtain copies of this document, contact: UHC/BCS

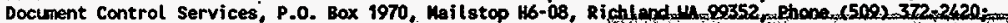
Fax (509) 376-4989.
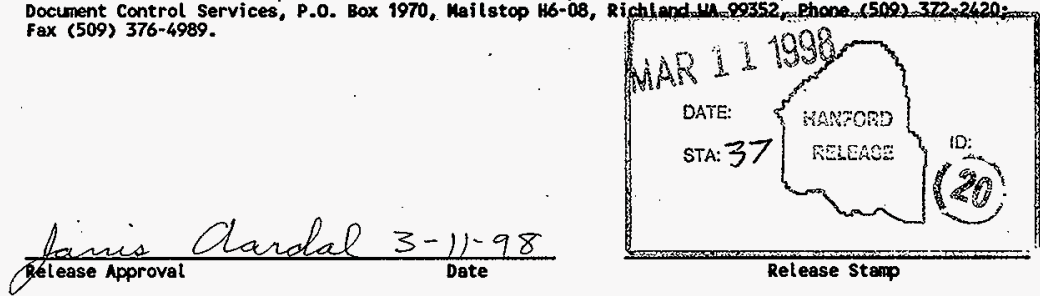


\section{LIGHT DUTY UTILITY ARM STARTUP PLAN}

\section{HNF-2300 \\ Rev. 0}

\section{G. A. Barnes \\ SGN Eurisys Services Corporation}

February, 1998 
Table of Contents

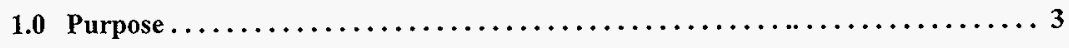

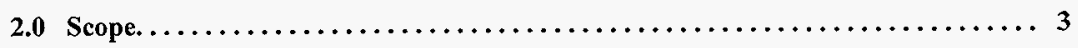

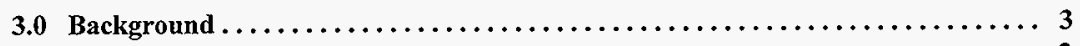

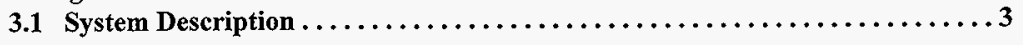

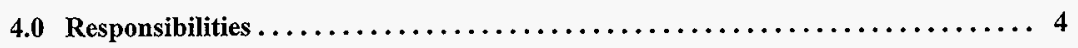

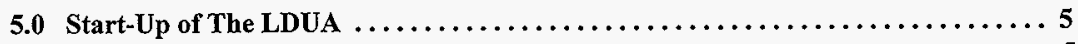

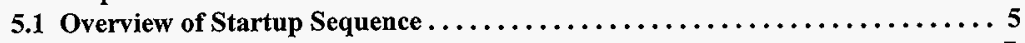

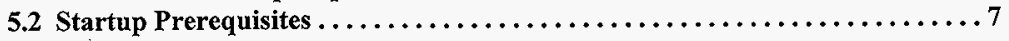

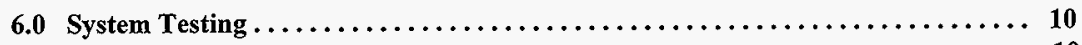

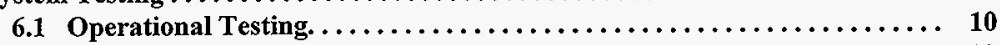

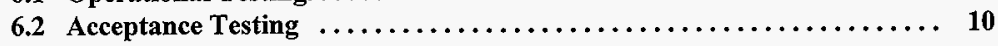

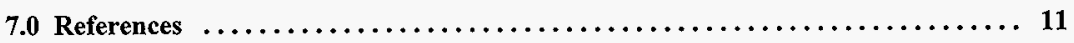

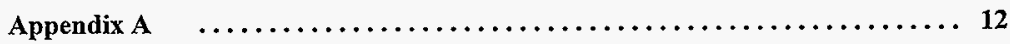




\section{LIGHT DUTY UTILITY ARM STARTUP PLAN}

\subsection{PURPOSE}

This plan details the methods and procedures necessary to ensure a safe transition in the operation of the Light Duty Utility Arm (LDUA) System. The steps identified below outline the work scope and identify responsibilities to complete startup, and turnover of the LDUA to Characterization Project Operations (CPO).

\section{$2.0 \quad$ SCOPE}

This Startup Plan encompasses activities necessary to perform startup and operation of the LDUA in Facility Group 3 tanks and complete turnover to CPO. The activities discussed in this plan will occur prior to, and following the U.S. Department of Energy, Richland Operations Office (RL) Operational Readiness Review (ORR). Contained in Appendix A is the baseline schedule that lists system startup and turnover activities.

This startup plan does not authorize or direct any specific field activities or authorize a change of configuration. As such, this startup plan need not be Unresolved Safety Question (USQ) screened.

\subsection{BACKGROUND}

\subsection{SYSTEM DESCRIPTION}

The LDUA is a mobile, multi-axis positioning system capable of accessing tanks through existing 12-inch diameter and larger tank dome risers. This system provides a flexible robotic platform designed to exercise tools called end effectors for accomplishing activities such as in situ inspection, waste assessment, equipment deployment, and sampling. The end effectors are mounted on the end of the LDUA by attachment to a tool interface plate (TIP) with mating service connectors.

The various end effectors are deployed into tanks to facilitate requirements such as surveillance, inspection, waste characterization, and movement of in-tank equipment. The end effectors may be locally waste disturbing near the waste surface (up to 12 inches deep) by probing, scraping, grabbing or sampling tank waste at various locations within the tank. In addition, the end effectors may be used to place monitoring equipment onto or into tank waste.

Major components of the LDUA system are as follows:

- End Effectors: end effectors are the tools that perform the specific in-tank tasks of the LDUA system; 
- Light Duty Utility Arm: the light duty utility arm is a robotic manipulator (having seven degrees of freedom) that provides dexterity to reach around obstructions in the tank while orienting and positioning end effectors to any surface within its operating envelope;

- Tank Riser Interface and Confinement (TRIC) System: the TRIC system provides an interface between the LDUA system and the waste tank riser, and is used for change-out of end effectors, minor maintenance tasks, and containment of the tank atmosphere;

- Vertical Positioning Mast: the vertical positioning mast provides the gross vertical positioning of the LDUA above the waste;

- Mobile Deployment System: the mobile deployment system is used to transport the LDUA between and within tank farms;

- Operations Control System: the operations control system includes most of the control and data acquisition equipment for the LDUA system, consisting of the operations control trailer, the at-tank instrument enclosure, the supervisory control and data acquisition system, and the control network;

- Operations Control Trailer: the operations control trailer is a standard semi-trailer that is towed to the tank farm and parked outside the perimeter fence. It provides two separate work areas - the operating area, containing the control panels and workstations which control the LDUA system; and the visitor area, containing desks, shelves, data access workstations, and other staff amenities;

- Utilities: electrical systems, compressed gas systems, and decontamination wash water supply system.

\subsection{RESPONSIBILITIES}

The LDUA Startup Team has been formed with key personnel from the Hanford Tanks Initiative (HTI) and Characterization Project. Cognizant Engineering and Design Authority support is provided by Characterization Equipment Engineering. The LDUA Startup Team and the individual responsibilities for each activity are provided in Appendix A.

CPO will specifically train a selected group who will work with the LDUA Startup Team to provide operations support for startup of the LDUA. This selected group consists of two Persons In Charge (PIC), seven Nuclear Process Operators (NPO) and various other maintenance and radiological control personnel. The Operations Shift Manager will release work activities in this startup sequence and direct the startup team to proceed. When appropriate, a senior supervisory watch will observe the activity. 


\subsection{START-UP OF THE LDUA}

\subsection{OVERVIEW OF STARTUP SEQUENCE}

Startup of the LDUA (deployment in tank AX-104) will consist of the following activities:

- Install Utilities - This activity will provide appropriate utilities to AX-farm to power the LDUA system. It is anticipated that this activity will be completed prior to the completion of the RL ORR.

- Move LDUA to AX-farm - This activity will consist of moving the LDUA equipment from the Cold Test Facility (CTF) in the 400 area to AX-Farm.

- Setup equipment at AX-farm - The LDUA system will be setup for deployment into $\mathrm{AX}-104$, as depicted in Figure 1. 


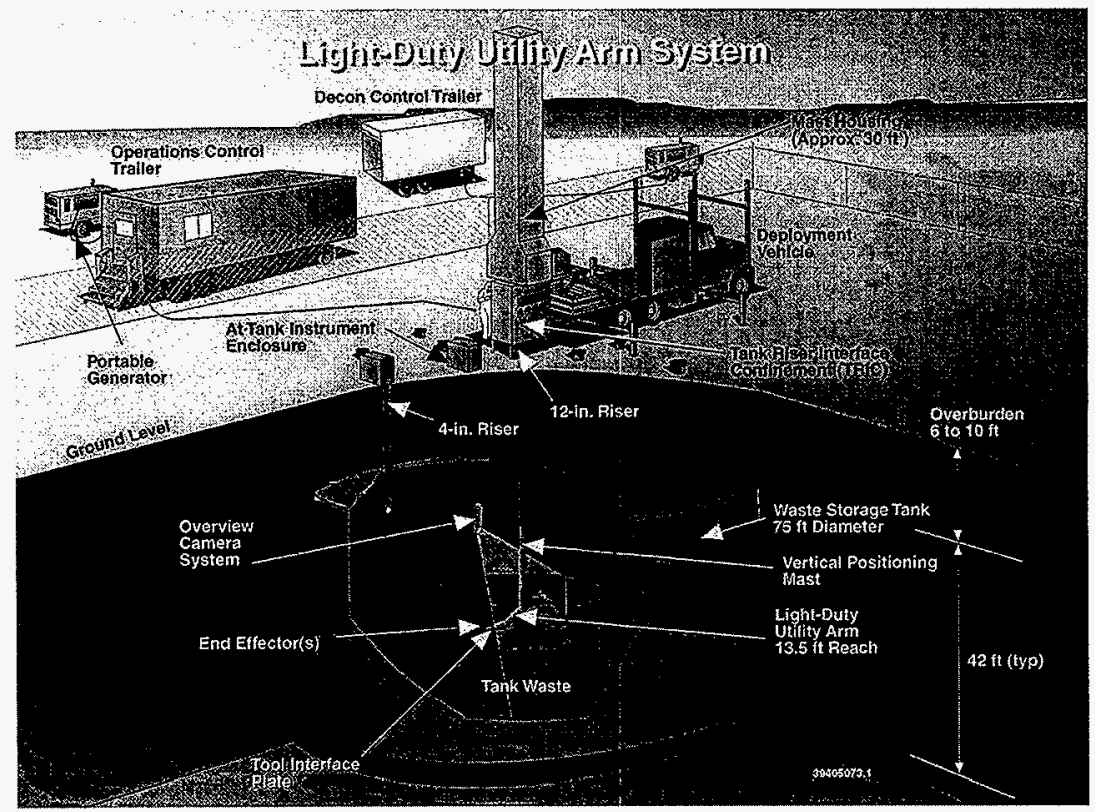

Figure 1

- Deploy LDUA in AX-104/Complete Campaign - The LDUA system will be deployed into tank AX-104 and sampling will be conducted with the Extended Reach End Effector (EREE). Approximately 15 samples will be retrieved from the bottom, side-walls and dome (Tank 241-AX-104 Light Duty Utility Arm Sampling and Analysis Plan, HNF-2071). Video inspection of the interior of AX104 will also be conducted during deployment with the High Resolution Stereo Video System (HRSVS) end effector.

- Ship Samples to 222S - The samples obtained during the LDUA deployment will be shipped to the $222 \mathrm{~S}$ laboratory for analysis.

- Remove Equipment - At the completion of the deployment, the LDUA will be removed from the tank and all associated equipment will be placed in storage.

- Remove Boot - During this activity, the LDUA will be moved to TX farm where it will be deployed into an empty caisson. As the LDUA is lowered into the TX farm caisson, the protective rubber boots will be removed. The LDUA will also be decontaminated at this time, if required. 
- Transport to Storage - Upon successful decontamination of the LDUA, the LDUA system and all subsystems will be transported to storage.

\subsection{STARTUP PREREQUISITES}

Prior to commencing the Startup activities, it must be confirmed that the Department of Energy, Richland Operations Office (RL), Operational Readiness Review (ORR) has been completed and $\mathrm{RL}$ has issued authorization to startup.

Prior to the RL ORR, the following items must be completed:

- RL must release the hold on LDUA field activities. The hold on LDUA field activities occurred in February of 1997 and it will not be lifted until RL is satisfied that there is adequate authorization basis for the LDUA system.

- All ORR prerequisites are completed. The following is a list of $O R R$ prerequisites:

- Preparation and approval of LDUA system Preventive Maintenance (PM) and calibration procedures. The basis for the scope of the PM procedures is detailed in PNNL document, PNNL-LDUA-PMR-97211701, (VI \# 22803). The scope of the calibration program is based on the LDUA safety equipment list (HNF-2147) and the Flammable Gas Equipment Advisory Board (FGEAB) letter (FGEAB-97-019, Rev 2, September 9, 1997.) A total of 6 PM and calibration procedures are required.

- Revision and approval of the LDUA Plant Operating Procedures (POP). The LDUA POPs were first prepared in FY-96 for the initial deployment of the LDUA in tank T-106 and must be revised to include controls from the $\mathrm{BIO}$, TSRs and FGEAB requirements. A total of 7 POPs are required.

- Reconcile POPs to the Authorization Basis. Preparation of the POPs was largely performed prior to finalization of the $\mathrm{AB}$. $\mathrm{CPO}$ personnel will verify that the POPs have incorporated all controls from the authorization basis documents.

- Prepare and approve work package. The work package is the first line work authorization document. It includes instructions, permits, dome load calculations and other documentation required for the operating crew to safely deploy the LDUA. This activity cannot be completed until the POPs are approved.

- Setup operator training program. This task will include preparation of all operator training documentation. The training documentation will be adequate to qualify the operations personnel to operate the LDUA. The documentation will include training handouts, OJT cards, examinations and training plan. 
- Operator Training. Operator training will occur in the Cold Test Facility (CTF) in the 400 area. Operator training will begin before the training program is complete, however the operators will not be qualified until they attend the classes and pass the exam. In addition, the POPs will be validated during the initial phase of operator training.

- Setup maintenance training program. The CPO maintenance personnel will be maintaining the LDUA after the system is turned over. This activity will prepare the training program for CPO maintenance personnel. The maintenance training program will focus on orientations to the LDUA systems and LDUA PM and calibration procedures, rather than component-specific training.

- Maintenance training. Maintenance training of CPO personnel will occur after the maintenance training program is setup. Maintenance training cannot occur until after the PM and calibration procedures are completed.

- Safety documentation for the Extended Reach End Effector (EREE). Safety documentation for the EREE must be completed. The safety documentation for the EREE includes preparation of a Hazards Identification and Evaluation (HIE) and preparation of a USQ screening/determination. The information in the HIE will feed into the POPs and other documentation, as required.

- Review procedures for conduct of operations. The scope of this activity is to review the operations procedures to verify that all aspects of the conduct of operations program are considered.

- Review calibration, testing and PMs. A separate review of the PM and calibration procedures will be conducted to verify adequacy.

- Place PMs and calibrations on recall. This activity will place all PM and calibration items identified during the preparation of the PM and calibration procedures in the CPO preventive maintenance and calibration recall system. This task will also review the current status of the LDUA PMs and calibrations.

- Calibrate LDUA instruments and perform PMs. This activity will consist of preparation of the work packages and performing the calibrations and maintenance on the LDUA system. This activity cannot start until the calibration and PM procedures are approved and maintenance personnel are adequately trained.

- Review HATS and DTS. This activity will review the various tracking systems associated with CPO and TWRS to verify there are no issues that could affect the LDUA deployment 
- Identify changes to S/RIDS. The scope of this activity is to review the current S/RLDS program to verify that the startup of the LDUA does not change any of the requirements within the S/RIDS.

- Prepare SEL. A LDUA system Safety Equipment List (SEL) will be prepared. The SEL will provide requirements for calibration and dedication of Commercial Grade Items (CGI)

- Prepare CGI. CGI data sheets will be prepared during this activity. The CGI data sheets will be based on the SEL. Completion of the CGI forms will document the dedication of commercial grade items to the appropriate Safety Class, Safety Significant or GS-DID level.

- Prepare essential drawings. Essential drawings will be prepared and released that identifies the safety equipment identified in the SEL.

- Prepare storage plan. A storage plan will be prepared that identifies the storage location for the LDUA after deployment in AX-104. The selected storage location must allow storage of radioactive material and must provide adequate electrical utilities for operating the HVAC systems and maintaining climate control of the various LDUA systems

- Complete ABU Punchlist. In addition to the previously listed activities, the following tasks must be finished to complete the Acceptance for Beneficial Use (ABU) punchlist:

- Issue Documents to CVI. Prior to turnover of the LDUA system to Operations, all design and vendor documentation will be transmitted to the Vendor Information (VI) file.

- Issue ATP. The LDUA Phase 2 qualification test report (HNF-SD-WMATR-196) must be issued. Phase 2 qualification testing verified that the LDUA met the flammable gas control imposed by the FGEAB (FGEAB97-019, Rev 2, September 9, 1997)

- Issue Test Report. The vendor, (PNNL), will issue the EREE test report. The EREE test report will then be transmitted to the VI file.

- Issue O\&M Manuals. The Operations and Maintenance manuals that were prepared by the vendors of the LDUA system will be issued.

- Complete Spare Parts Inventory. This task will include preparation of the recommended spare parts list by the vendor (PNNL) and verification that recommended spare parts are available for LDUA startup.

- Release vendor drawings to CVI. This task will update all LDUA vendor drawings to include red line changes identified after delivery of the system. The updated vendor drawings will be released by the vendor 
(PNNL) with vendor QA review. The updated vendor drawings will then be transmitted to the VI file.

- Issue ABU. Once the above tasks are completed, a final $\mathrm{ABU}$ checklist will be issued. Issuance of the $A B U$ will be tied to completion of the management self-assessment.

- Review Environmental Permits. A review of environmental permits associated with the LDUA system will be performed to verify that all environmental permits associated with LDUA startup are current and approved.

- Prepare drill Scenarios. Various drill scenarios will be prepared to verify that the operations team is adequately trained for typical emergency responses.

- Management observe drills. Once the drill scenarios are prepared, management will observe and evaluate the team's performance while conducting these drills.

- Develop design compliance matrix. The design compliance matrix will identify all design criteria that was used to develop the LDUA system and it will also detail how the design criteria has been met.

\subsection{SYSTEM TESTING}

\subsection{OPERATIONAL TESTING}

Operational testing of the LDUA has been completed. The scope of the operational testing is detailed in WHC-SD-WM-OTP-213, Rev. 0 . The results of the operational testing are detailed in HNF-SD-WM-OTR-213, Rev. 0. No additional operational testing is anticipated at this time.

\subsection{ACCEPTANCE TESTING}

Acceptance testing was performed in two parts: Phase 1 qualification (acceptance) testing was performed in fiscal year, 1996, per ATP-WHC-SD-TD-ATP-005 and the results are detailed in WHC-SD-TD-ATR-005. Phase 2 qualification (acceptance) testing was performed in fiscal year 1997 per WHC-SD-WM-ATP-196 and the results are detailed in WHC-SD-WM-ATR-196. No additional acceptance testing is anticipated at this time. 


\subsection{REFERENCES}

1. FGEAB-97-019, Rev 2, "Flammable Gas Equipment Advisory Board Interpretation/ Recommendation Report," dated September 9, 1997.

2. HNF-2071, Rev. 0, "Tank 241-AX-104 Light Duty Utility Arm Sampling and Anlysis Plan", dated February, 1998.

3. HNF-2147, Rev 0, "Safety Equipment List for the Light Duty Utility Arm System," dated February, 1998.

4. HNF-SD-WM-ATP-196, Rev 0, "Light Duty Utility Arm Equipment Qualification Test Procedure", 1997.

5. HNF-SD-WM-ATR-196, Rev 0, "Light Duty Utility Arm Equpement Qualification Test Report", 1997.

6. HNF-SD-TD-ER-005, Rev. 1, "Light Duty Utility Arm Baseline System Description", dated December, 16, 1996.

7. HNF-SD-WM-OTR-213, REV 0, "Light Duty Utility Arm (LDUA) Operability Test Report, dated October, 1996.

8. Letter, J.K. McClusky, RL to H.J. Hatch, FDH, "contract Number DE-AC06-96RL13200, Directed Hold on Tank Intrusive Activities With the Light Duty Utility Arm (LDUA) and Push Mode Sampling," 9751787, dated February 27, 1997.

9. PNNL-LDUA-PMR-97211701, (contained inf VI file \# 22803), "Integrated LDUA System Preventive Maintenance Requirements, dated December 30, 1997.

10. WHC-SD-WM-OTP-213, Rev 0, "Operability Test Procedure for the Light Duty Utility Arm in Tank T-106", dated 1996

11. WHC-SD-WM-TD-004, Rev 0, "Light Duty Utility Arm Qualification Test Procedure," 1996.

12. WHC-SD-WM-TD-004, Rev 0, "Light Duty Utility Arm Qualification Test Report," 1996.

13. LMHC-97-61734, "Light Duty Utility Arm Plan of Action", dated December18, 1998.

14. LMHC, Draft "Light Duty Utility Arm Plant Readiness Plan", Dated February, 1998 
HNF-2300, Rev. 0

Page 12 of 12

\section{APPENDIX A}

DSI, Bill Root to D. Shuford et al, "FY-98 LDUA Schedule/Cost Estimate" Dated December 29, 1997, 9 pages (including cover). 
DON'T SAY IT -.. Write It!

TO: D.H. Shuford

R.S. Popielarczyk

S7-01

J. G. Burton

R.M. Boger

D.O. Dobson

J.D. McDonald

C.A. Esvelt

W.J. Kennedy

T.C. Bender

J.M. Mooris

T.E. Rainey

G.A. Barnes
S7-01

S7-21

S7-12

R2-50

R2-50

S7-12

S7-03

R2-83

R2-87

H6- 12

B4-51
DATE: $12 / 29 / 97$

FROM: Bill Root

Telephone: 373-1328

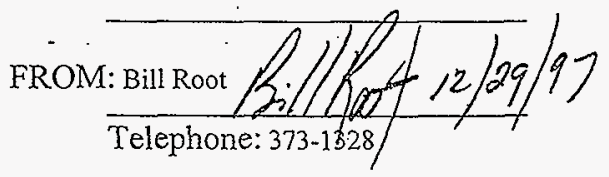

\section{SUBJECT: FY.98 LDUA SCHEDULE/COST ESTIMATE}

Attached, please find a copy of the approved schedule/cost estimate and statements of work for the FY-98 LDUA deployment and sampling activities. If you have any questions, please contact either Geoff Barnes at 376-2241 or Tom Rainey at 373-3531. 


\section{HTr FX-98 Scope Statements \\ Task: 1D2CL50K02 - LDUA Deployment}

\section{CHARACTERIZATION OPERATIONS}

Scope Statement: Provide Operations personnel to support the LDUA deployment in tank 241AX-104 as identified in the attached schedule/cost estimate. 'This support shall include LDUA operator and maintenance training, Plarit readiness preparation for the Operational Readiness Review (ORR); transport of the LDUA equipment to AX-farm, setup of LDUA equipment at AX-farm, operation/sampling with the LDUA in tank 241-AX-104, removal and decontamination of the LDUA equipment when the deployment is completed and transport of the LDUA equipment to storage.

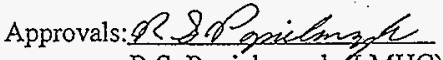

R.S. Popielarczyk (LMHC)

\section{CHARACTERIZATION ENGINEERING}

Scope Statement: Provide cognizant engineering and Design Authority support for the deployment of the LDUA in tank 241-AX-104 as identified in the attached schedule/cost estimate. This support shall include preparation of all operations and calibration/maintenance procedures for the LDUA, all USQ documentation that is required to deploy the LDUA, design authority review and approval of all design baseline documentation, cognizant engineering review and approval of all field work packages, coordination of all appropriate reviews and approvals of operating and maintenance/calibration procedures, field work packages and other required documentation and support of the $O R R$, as required..

Approvals:

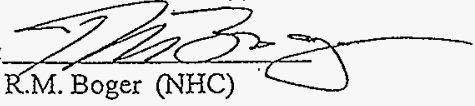

TESTING AND SYSTEM READINESS

PSEPARE FOR AND

Scope Statement: Provide personnel (site and/or contractor personnel, as required) totperform the LDUÅ유 per the attached schedule/cost estimate. This task shall include

preparation/approval of the ORR Implementation Plan, ORR team selection and training REViEwER

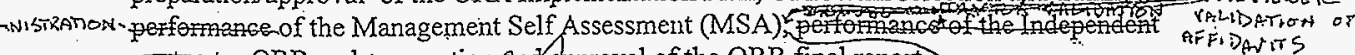
and preparation and approval of the ORR final report.

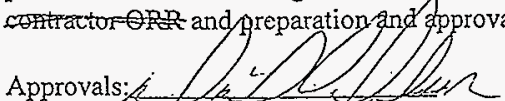
PROVIDE CONTRACTDR ORR
Approvals:
TEAM LEADER,

Do. Dobson (LAHC)

\section{TANK FARMS OPERATIONS TRAINING}

Scope Statement: Prepare LDUA operations training program and LDUA maintenance training programs per the attached schedule/cost estimate. Provide training for Operations and Maintenance personnel per the attached schedule/cost estimate. 
HNF-2300, Rev. 0

Page A-3

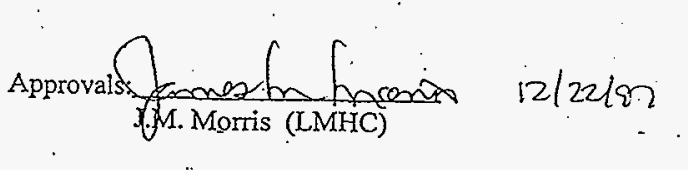

HT LEVA DEPLOYMENT

Scope Statement: Manage the tasks identified in the attached schedule/cost estimate. Perform tasks identified as RESP in the attached schedule/cost estimate.

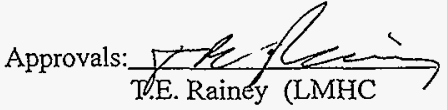

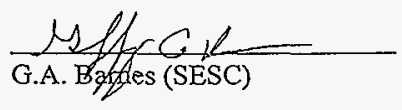




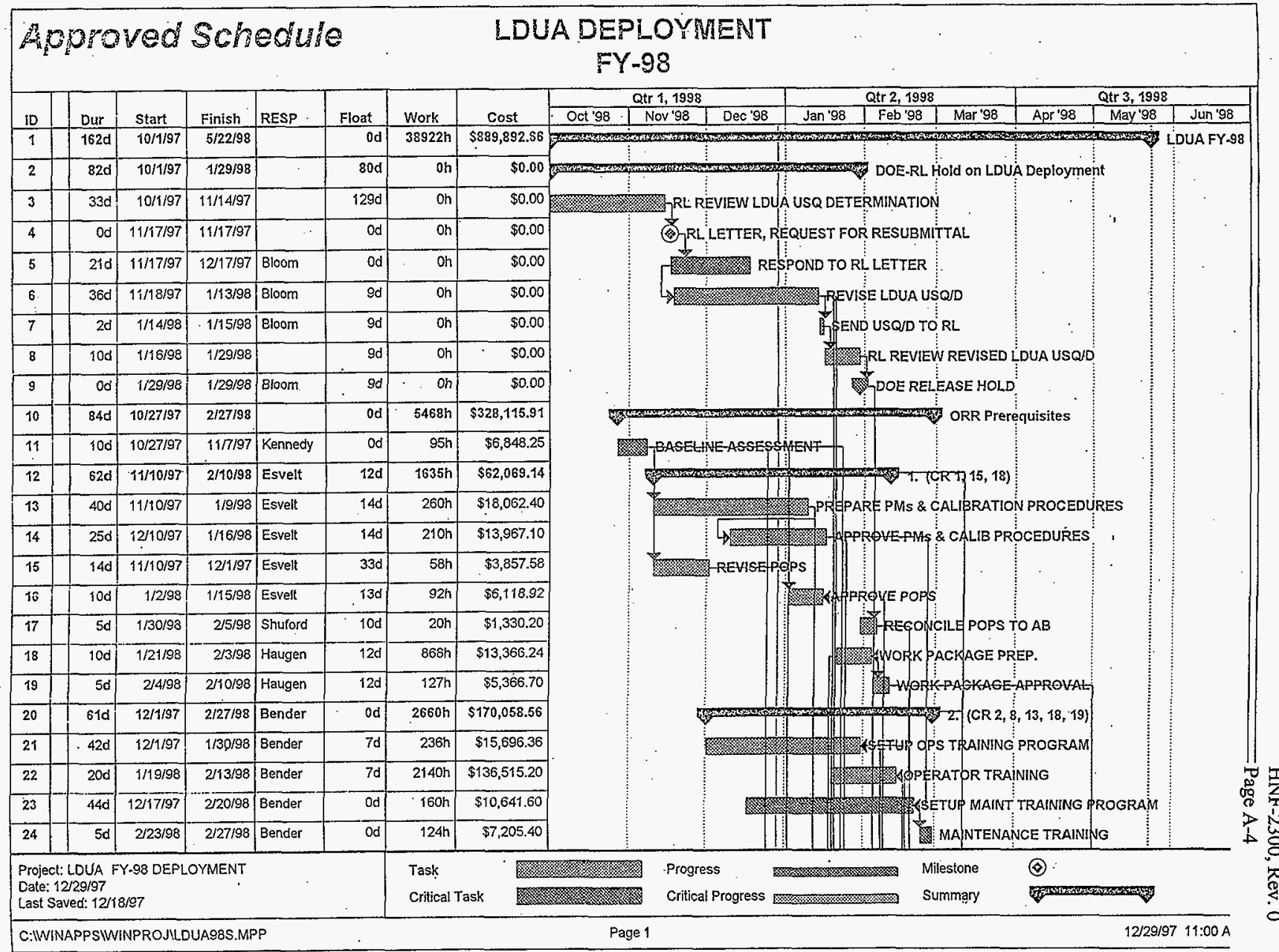




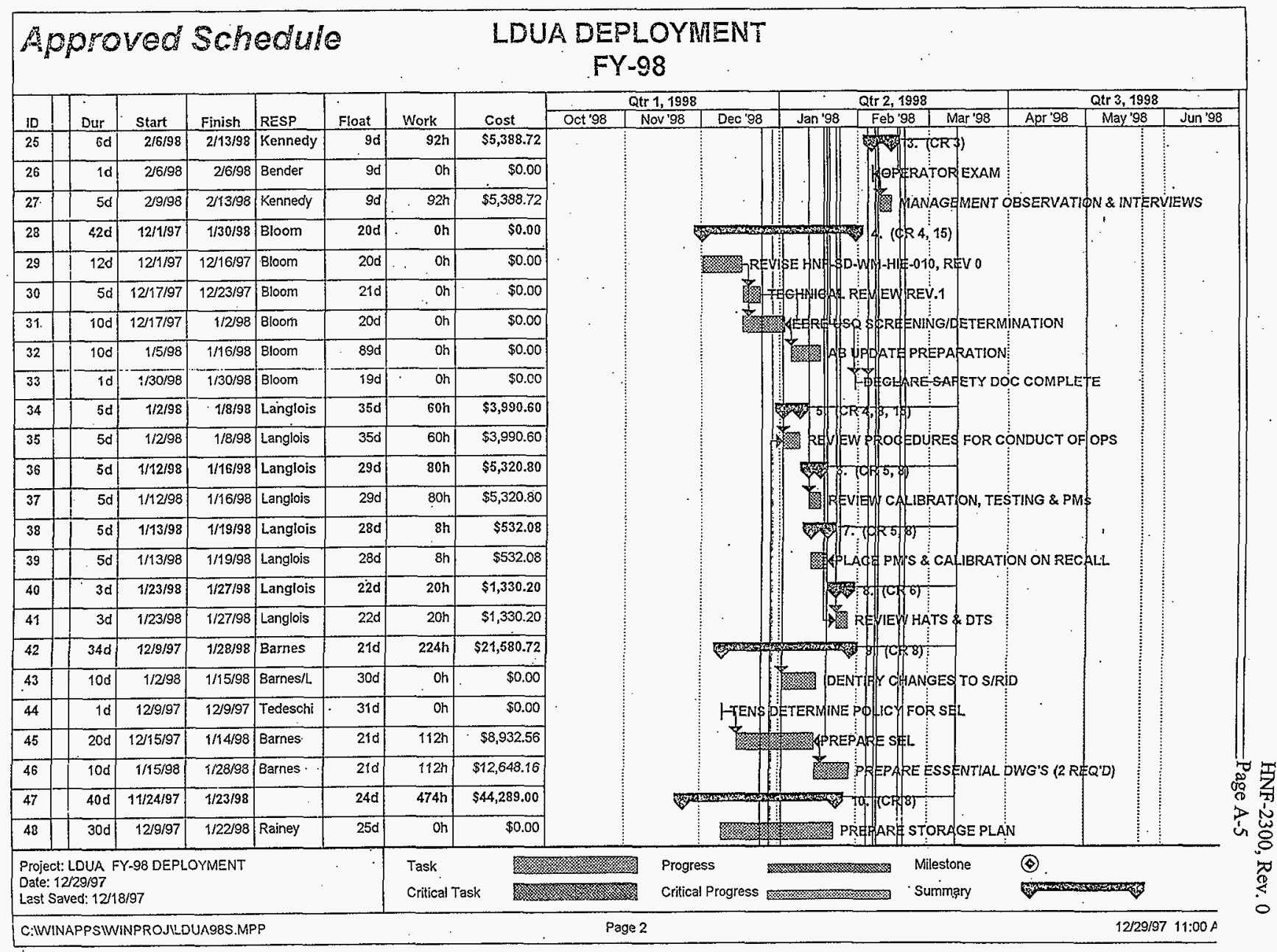




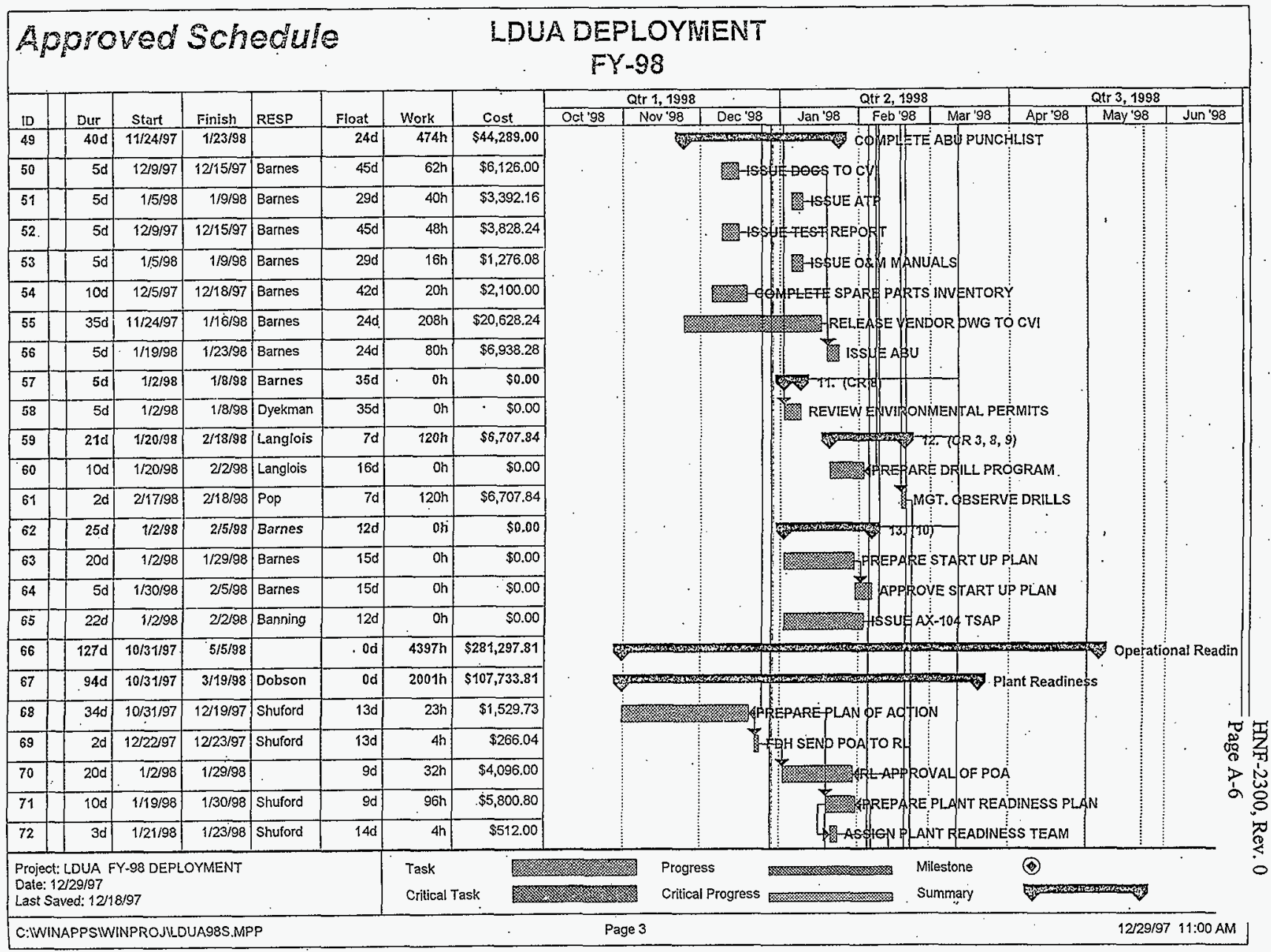




\section{Approved Schedule}

\section{LDUA DEPLOYMENT}

FY-98

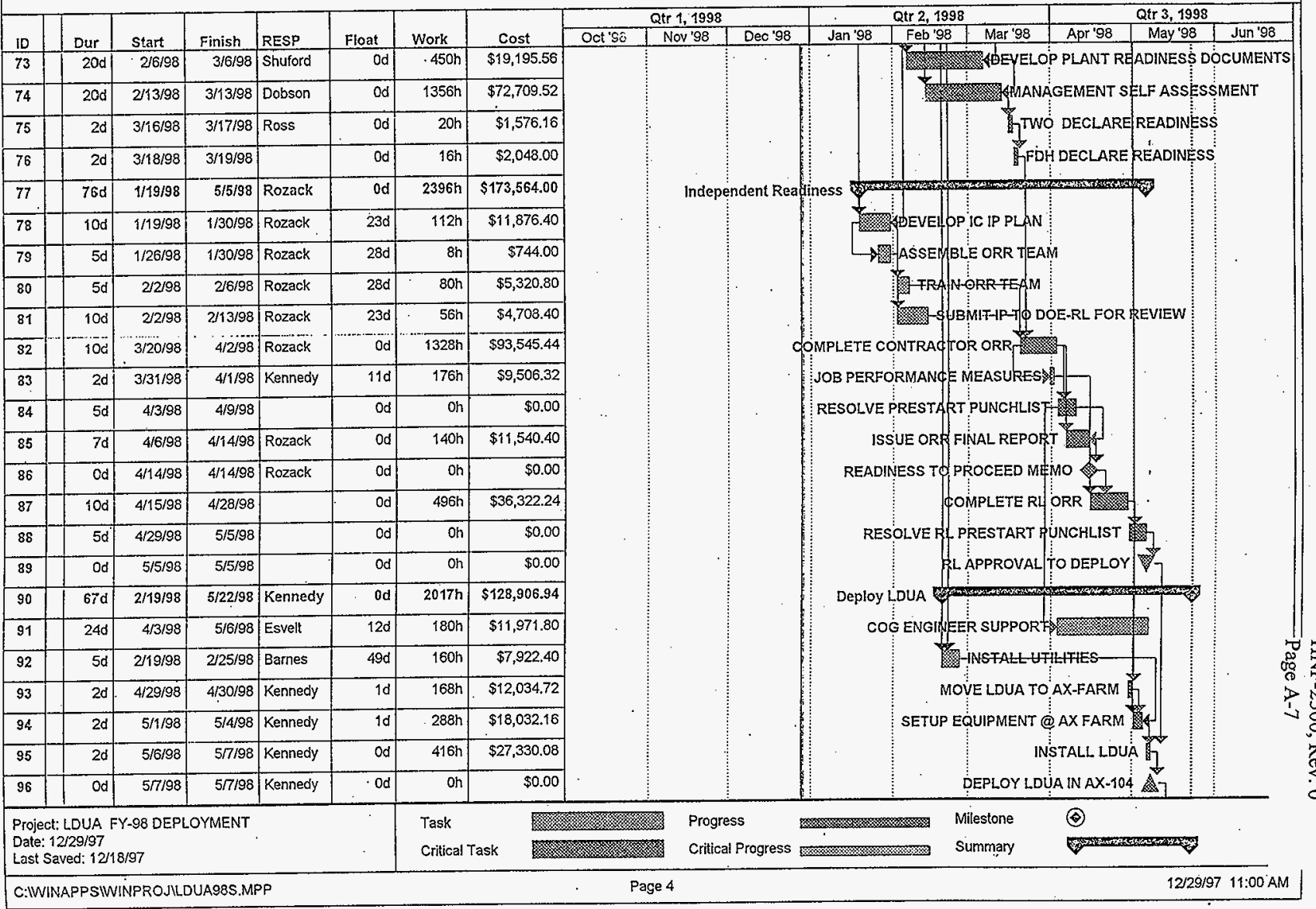




\section{Approved Schedule}

\section{LDUA DEPLOYMENT}

FY-98

\begin{tabular}{|c|c|c|c|c|c|c|c|c|c|c|c|c|c|c|c|c|}
\hline \multirow[b]{2}{*}{ ID } & \multirow[b]{2}{*}{ Dur } & \multirow[b]{2}{*}{ Start } & \multirow[b]{2}{*}{ Finish } & \multirow[b]{2}{*}{ RESP } & \multirow[b]{2}{*}{ Float } & \multirow[b]{2}{*}{ Work } & \multirow[b]{2}{*}{ Cost } & \multicolumn{3}{|c|}{ Qtr 1, 1998} & \multicolumn{3}{|c|}{ Qtr 2, 7998} & \multicolumn{3}{|c|}{ Qtr 3, 1998} \\
\hline & & & & & & & & Oct'98 & Nov' 98 & Dec '98 & $\operatorname{Jan} 198$ & Feb ${ }^{\prime} 98^{\circ}$ & Mar' 98 & Apr ' 98 & May' 98 & Jun 98 \\
\hline 97 & $9 d$ & $5 / 8 / 98$ & $5 / 20 / 98$ & Kennedy & Od & $637 \mathrm{~h}$ & $\$ 42,294.26$ & & & & & & COMPL & CAMP & & \\
\hline 98 & $5 d$ & $5 / 11 / 98$ & $5 / 15 / 98$ & Kennedy & od & $168 \mathrm{~h}$ & $\$ 9,321.52$ & & & & & & SHIP SA & ES T & & \\
\hline 99 & $2 d$ & $5 / 18 / 98$ & $5 / 19 / 98$ & Kennedy & od & $\mathrm{Oh}$ & $\$ 0.00$ & & & & & & & VE EQU & IT & \\
\hline 100 & $1 d$ & $5 / 20 / 98$ & $5 / 20 / 98$ & Kennedy & od & Oh & $\$ 0.00$ & & & & & & & REMO & OT & \\
\hline 101 & $2 d$ & $5 / 21 / 98$ & $5 / 22 / 98$ & Kennedy & od & On & $\$ 0.00$ & & & & & & TRANS & RT TOS & & \\
\hline 102 & od & $5 / 20 / 98$ & $5 / 20 / 98$ & & $2 d$ & Oh & $\$ 0.00$ & & & & & $04-98-51$ & APLE & DUA SA & & \\
\hline 103 & $156 \mathrm{~d}$ & $10 / 1 / 97$ & $5 / 14 / 98$ & Barnes & $6 d$ & $27040 \mathrm{~h}$ & $\$ 151,572,00$ & & & & & & & & & ation \& 0 \\
\hline 104 & $156 \mathrm{~d}$ & $10 / 1 / 97$ & $5 / 14 / 98$ & Barnes & $6 d$ & $600 \mathrm{~h}$ & $\$ 55,800,00$ & 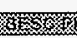 & 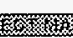 & 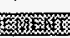 & & & & & & \\
\hline 105 & $130 \mathrm{~d}$ & $10 / 22 / 97$ & $4 / 30 / 98$ & Barnes & $16.13 d$ & $24960 \mathrm{~h}$ & $\$ 28,320.00$ & & & & & & & & LDUA Si & AGE \\
\hline 106 & $\operatorname{sod}$ & $1 / 2 / 98$ & $5 / 8 / 98$ & Langlois & $10 \mathrm{~d}$ & $1440 \mathrm{~h}$ & $\$ 63,252,00$ & & & & KS & 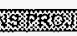 & 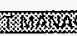 & 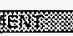 & & \\
\hline 107 & $1 d$ & $10 / 8 / 97$ & $10 / 8 / 97$ & Samuels & Od & $40 \mathrm{~h}$ & $\$ 4,200.00$ & LDUA & monstra & & & & & & & \\
\hline
\end{tabular}

Project: LDUA FY-98 DEPLOYMENT

Date: 12/29/97

Last Saved: $12 / 18 / 97$

C:WINAPPSWWINPROJMDUA98S.MPP
Task

Critical Task
Progress

Page 5
Milestone

summary
(4)

(5) 